ISSN 2693-2504

\title{
Mathematical Multiobjective Optimization for Metal Hip Arthroplasty with Medical Physics Applications
}

Journal of Bioscience \& Biomedical Engineering

Research Article

\author{
Francisco Casesnoves
}

PhD Engineering, MSc Medical Physics-Mathematics, MD. Medical Physics-Technology Research Scientist. IAAM (International Association of Advanced Materials, Sweden); Harjumaa, Estonia

\author{
*Correspondence authors \\ Francisco Casesnoves \\ $\mathrm{PhD}$ Engineering \\ MSc Medical Physics-Mathematics, \\ MD. Medical Physics-Technology Research Scientist. \\ IAAM (International Association of Advanced Materials, \\ Sweden) \\ Harjumaa \\ Estonia
}

Submitted : 19 Sept 2021 ; Published : 28 Oct 2021

\begin{abstract}
Total hip metal arthroplasty (THA) model-parameters for a group of commonly used ones is optimized and numerically studied. Based on previous ceramic THA optimization software contributions, an improved multiobjective programming method/algorithm is implemented in wear modeling for THA. This computational nonlinear multifunctional optimization is performed with a number of THA metals with different hardnesses and erosion in vitro experimental rates. The new software was created/designed with two types of Sytems, Matlab and GNU Octave. Numerical results show be improved/acceptable for in vitro simulations. These findings are verified with 2D Graphical Optimization and 3D Interior Optimization methods, giving low residual-norms. The solutions for the model match mostly the literature in vitro standards for experimental simulations. Numerical figures for multifunctional optimization give acceptable model-parameter values with low residual-norms. Useful mathematical consequences/calculations are obtained for wear predictions, model advancements and simulation methodology. The wear magnitude for in vitro determinations with these model parameter data constitutes the advance of the method. In consequence, the erosion prediction for laboratory experimental testing in THA add up to the literature an efficacious usage-improvement. Results, additionally, are extrapolated to efficient Medical Physics applications and metal-THA Bioengineering designs.
\end{abstract}

Keywords: Dual Nonlinear Optimization, Metal Artificial Implants (MAI), Hip Implants, Total Hip Arthroplasty (THA), MoM (Metal on Metal hip implant), In vivo experimental, In vitro clinical experimental, Objective Function (OF), Prosthesis Materials, Wear, Biomechanical Forces.

\section{Introduction}

In hard-bearings THA prostheses, the metal group is the second generic one in high magnitude hardness parameter, following ceramics. During the clinical practice, it is frequent to combine polyethylene cup with a metal head - namely, MoP THA. Ceramic materials is the generic group whose hardness magnitude is highest $[1,2,9,16,17,19]$. A post-operation inconvenient for patients is pain when moving the articulation. This happens specially with ceramic CoC implants, because of their high hardness magnitude. In previous contributions, $[1,2]$, THA ceramic modelling optimization was presented, $[2,3,4,6]$, for a multiobjective optimization, namely. (Zirconia $\left(\mathrm{ZrO}_{2}\right)$, Alumina $\left(\mathrm{Al}_{3} \mathrm{O}_{2}\right)$, ZTA (Zirconium Taughtened Alumina) Biolox, and ZTA Biolox-Delta. In that publication, $\mathrm{K}$ adimensional constant of the model had one magnitude order lower than K-metal THA determined in this research.

For wear prediction statistics database, experimental work in vitro involves THA wear simulations. These laboratory methods try to simulate in vivo conditions with a large variety of technical-apparatus and computational modelling optimization. In general, there are analytical models, and Finite Elements models. The analytical models could have also differential and integral calculus parameters. Table 1 shows a brief classification of the literature methods-variants and combinations [13-16,17].

It is difficult at in vitro experimental work to simulate with mathematical modelling precisely all the THA-wear factors once the prosthesis has been surgically implanted in the patient. Table 2 shows these difficulties, both in patients and external ones depending on the hospital staff and/or technical facilities. The anatomical zone has many normal conditions, such as important motion and spinal stabilization muscles, ligaments, combinations of biomechanical forces, gait, individual walking/movement habits, etc. Additionally could coexist pathological conditions, namely osteoporosis, associated 
diseases, fractures, osteonecrosis, osteomyelitis, etc.

From the biomechanical-dynamics point of view, the influence of kinetics and kinematics is essential to simulate in vitro THA wear. Hip kinetics, (loads, momentum, torque), is the most important factor as it comprises biomechanical forces and torques. Kinematics is also important, related to positioning, speed, and accelerations of the hip joint movement-Figure 1. The pathogenesis of hip articulation malfunction is caused statistically mostly by the high incidence/prevalence of femur neck fracture due to osteoporosis. This happens usually in elderly patients. According to statistics in Europe, Germany and Switzerland are the countries where a higher number of THA are surgically implanted/fixed [12].The load over the joint could be a traumatic loading or fall load. Both could cause a femur neck fracture provided the bone is weak, usually for ageing and/or osteoporosis, and/or associated pathologies.

In previous publications, [1], a classification of clinical factors related to THA surgery were presented. Namely, the PFTCF Hip Arthroplasty Functional Treatment Classification [Casesnoves, 2021]. PF are factors depending on patient, and TCF are technical-clinical factors of the hospital and/ or traumatology-orthopedics service. Table 2 presents this classification improved and explained.

The hip articulation biomechanical system is essential for locomotion and its biomechanical structure is rather complex for kinematics and kinetics. In brief, the optimal hip biodynamics depends on two factors. First one is the powerful muscles that perform the movement, walk and run mainly. Second is the strong ligaments that set the supporting forces to control correctly the muscles contraction/relaxation and also create constraints to guide and support/prevent/resist any biased movement. Main ventral muscles for walk and run that create hip rotation cycles are Psoas Major and Minor, Iliacus, Abductor Longis and Adductors system. At dorsal, Gluteus group is essential for locomotion. Most important ligaments are Iliofemoral (supporting),Pubofemoral(resisting), Iliolumbar (limiting), and ischiofemoral (resisting). In plain language, hip joint resembles a sophisticated-precise locomotion human machine with a wide range of movements/biodynamics. The energy-power is provided by the muscle system, while the ligaments and bones constitute the biomechanical framestructure. This biodynamical system has been geneticallyoptimized during the human evolution along million years.

Therefore, when setting a THA implant, there are two main objectives. The first one is to restore the approximately normal locomotion. The second is to resemble/configure biomechanically a system nearly equal to the normal onethe most difficult surgical-bioengineering challenge. It follows from these objectives that THA wear prediction/determination in post-surgical short-term and long-term is very important. Modelling therefore constitutes an efficacious method linked to these surgical purposes. The reason is that accurate models are related both to restoration duration of the approximately normal hip dynamics/motion and also to keep the hip biomechanical system constraints-muscles and ligaments that define the movement functionality. If THA wear damages the implant, severe complications associated to the whole hip biomechanical system and dynamical locomotion could occur. It is straightforward to guess the complexity of the hip joint biodynamics and the biomechanical modelling need.

In summary, this contribution presents an optimized model for THA metal hip wear for a group of widely used metal materials. Matlab and GNU Octave Systems are applied and compared for the optimization software design [1,2,6,22-25]. Results show be accurate with low residual-norms. Imaging graphs in 2D Graphcal of Opimization and 3D Interior Optimization confirm/validate the sowtware numerical results. Applications on Medical Physics and Biomedical engineering emerge from the mathematical results.

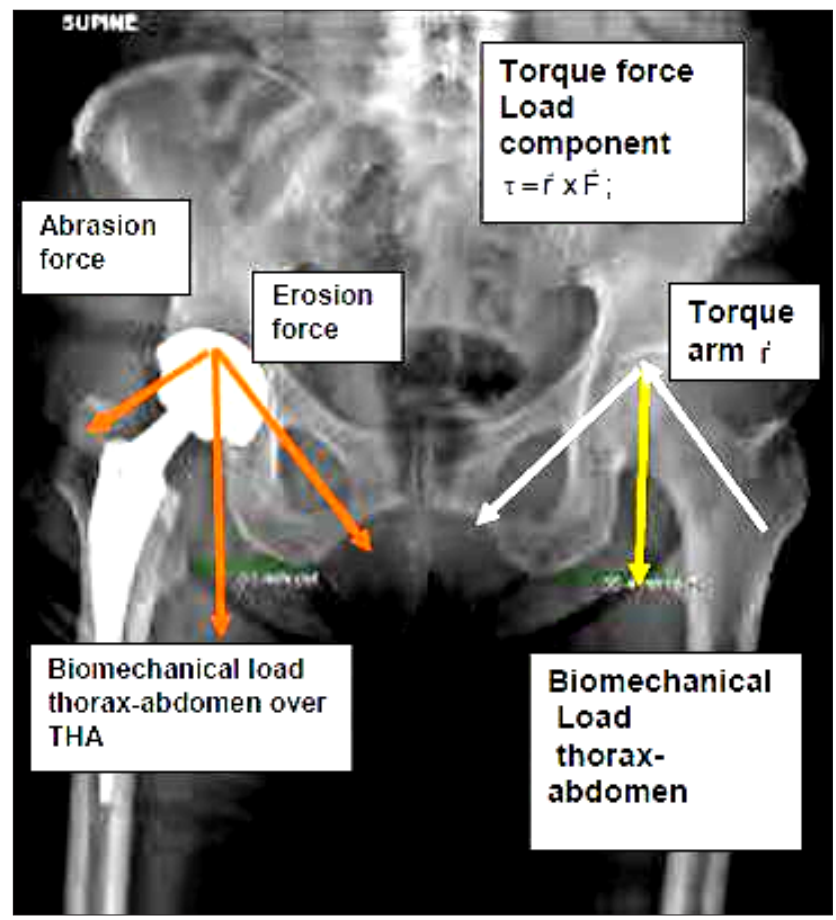

Figure 1: Sketch of Clinical Biomechanics for THA. The torque creates the fracture of femur neck when it has osteoporosis, for example usually, in elederly women. Pictured inset left, the distribution of biomechanical loads that cause abrasion/wear in the THA implant. [Google free images modified and drawn by author]. 


\begin{tabular}{|c|c|c|c|}
\hline Type & \multirow[t]{2}{*}{ ANALYTICAL } & \multirow[t]{2}{*}{ NUMERICAL } & \multirow[t]{2}{*}{ HYBRID } \\
\hline Properties & & & \\
\hline Equations(s) & $\begin{array}{l}\text { Simple in } \\
\text { general }\end{array}$ & $\begin{array}{l}\text { Finite Elements } \\
\text { Numerical methods for analytic } \\
\text { equations }\end{array}$ & $\begin{array}{l}\text { Finite Elements } \\
\text { with analytic equations }\end{array}$ \\
\hline $\begin{array}{l}\text { Discrete/ } \\
\text { Continuous }\end{array}$ & $\begin{array}{l}\text { Usually discrete, but also integral- } \\
\text { differential models }\end{array}$ & Discrete & $\begin{array}{l}\text { Discrete in Finite elements, but } \\
\text { continuous equations } \\
\text { Analytic can be done } \\
\text { Discrete or continuous }\end{array}$ \\
\hline $\begin{array}{l}\text { Linear/ } \\
\text { Non-linear }\end{array}$ & $\begin{array}{l}\text { Linear without } \\
\text { Separated hardness parameter } \\
\text { Non-linear otherwise }\end{array}$ & $\begin{array}{l}\text { Finite Elements } \\
\text { Linear and Non-Linear } \\
\text { Analytic linear and Non-linear } \\
\text { calculated numerically }\end{array}$ & $\begin{array}{l}\text { Depending of Finite Elements and } \\
\text { Equations } \\
\text { combinations }\end{array}$ \\
\hline
\end{tabular}

Table 1: Brief classification for THA modelling types

\begin{tabular}{|c|c|c|}
\hline Type & $\begin{array}{l}\text { PF } \\
\text { (Patient Factors) }\end{array}$ & $\begin{array}{l}\text { TCF } \\
\text { (Technical-Clinical Factors) }\end{array}$ \\
\hline FACTOR TYPE & $\begin{array}{l}\text { Patient anatomy } \\
\text { Ostheoporosis } \\
\text { Age } \\
\text { Individual patient kinetics/dinamycs } \\
\text { Optimal THA individualized } \\
\text { Inmunology } \\
\text { Histocompatibilty } \\
\text { Associated } \\
\text { Pathologies } \\
\text { Infection } \\
\text { (resistance to radiation for eliminating } \\
\text { infection) } \\
\text { Risk Factors: } \\
\text { Head size }<50 \text { mm } \\
\text { Acetabular inclincation }>50 \text { degrees } \\
\text { Severe pain } \\
\text { Bilateral implants } \\
\text { HR (head radius) }<44 \text { mm head } \\
\text { Female } \\
\text { Inmunosupresion drugs (any type) } \\
\text { Renal insufficiency } \\
\text { Suboptimal device alignment } \\
\text { Suspected metal sensitivity } \\
\text { Severely overweight } \\
\text { High levels of physical activity }\end{array}$ & $\begin{array}{l}\text { Imaging equipment available } \\
\text { Surgical staff available } \\
\text { Operation time available at surgical } \\
\text { theater } \\
\text { Technical equipment } \\
\text { Instrumentation functionality } \\
\text { Hospital functionality } \\
\text { Type of THA } \\
\text { Economical factors } \\
\text { Country technology in } \\
\text { Industrial Medical Technology } \\
\text { Precision in pre-operative diagnosis, } \\
\text { imaging diagnosis and evaluation } \\
\text { Rehabilitation programs } \\
\text { Possibily of individual prostheses } \\
\text { designs }\end{array}$ \\
\hline
\end{tabular}

Table 2: PF-TCF classification for hip arthroplasty surgical treatment [Casesnoves, 2021]. It is improved from a previous publication [2].

\section{Materials and Simulation Data}

Materials selected for multiobjective optimization are Stainless Steel(316-316L)Co-Cr-Mo(Ni,Fe, Co-based-alloys), Titanium alloy [3,9,17-21].Their physical characteristics are detailed in table 3.The material and corresponding experimental in vitro erosion data is taken from the literature $[1,2,3,9,17,20,21]$. In this study, experimental metal wear intervals are implemented from [33]. However, for THA ceramic modelling optimization in previous studies, other authors' publications were considered $[1,2,3,9,17,20,21]$. In all cases, units were adapted on $\mathrm{kg}, \mathrm{mm}$, and $\mathrm{mm}^{3}$ criteria.

Table 3 shows the material selection data within computational intervals. The reason is that actually there are many variants of Titanium alloys, Stainless Steel, and Co-Cr-Mo $[1,2,7,8]$. Provided the units are set in $\mathrm{mm}, \mathrm{mm}^{3}, \mathrm{~kg}$, and $\mathrm{s}$, the standard 
$\mathrm{K}$ parameter of the model becomes adimensional $[1,2]$. This constitutes an advantage for simplicity/easy calculations with experimental data calculations and programming simulations in vitro. These so-defined intervals are very important when setting numerical data into the simulation software.

\begin{tabular}{|c|c|c|c|}
\hline Material & $\begin{array}{l}\text { Hardness (Hv) } \\
\text { and } \\
\text { Histocompatibility }\end{array}$ & $\begin{array}{l}\text { Density } \\
\left(\mathrm{g} / \mathrm{cm}^{3}\right)\end{array}$ & $\begin{array}{l}\text { Cup Head } \\
\text { D i a m e t e r } \\
(\mathrm{mm})\end{array}$ \\
\hline $\begin{array}{l}\text { Stainless } \\
\text { Steel } \\
\left(\begin{array}{ccc}3 & 1 & 6\end{array}-\right. \\
316 L)\end{array}$ & $\begin{array}{l}316 \in[155,340] \\
316 L \in[199,225] \\
\text { Average }\end{array}$ & $\begin{array}{l}8.80 \\
8.02\end{array}$ & $28[22-28]$ \\
\hline $\begin{array}{l}\text { Co-Cr-Mo } \\
\text { (Ni, Fe, } \\
\text { Co-based- } \\
\text { alloys) }\end{array}$ & $\begin{array}{l}{[239,298]} \\
\text { Average-good }\end{array}$ & {$[7.80,9.15]$} & $28[22-28]$ \\
\hline $\begin{array}{l}\text { Titanium } \\
\text { alloy }\end{array}$ & $\begin{array}{l}{[122,245]} \\
\text { excellent }\end{array}$ & {$[4.43,4.66]$} & 28 [22-28] \\
\hline \multicolumn{4}{|c|}{ OPTIMIZATION DATA INTERVALS } \\
\hline \multicolumn{2}{|c|}{ Hardness (GPa) } & \multicolumn{2}{|c|}{$[1.8633,3.5303]$} \\
\hline \multicolumn{2}{|c|}{$\begin{array}{l}\text { Experimental } \\
\text { Erosion } \\
\left(\mathrm{mm}^{3} / \mathrm{Mc}\right)\end{array}$} & \multicolumn{2}{|c|}{$[0.001,2.000]$} \\
\hline \multicolumn{2}{|c|}{$\begin{array}{l}\text { Complementary } \\
\text { Data }\end{array}$} & \multicolumn{2}{|c|}{$\begin{array}{l}\text { ElasticityModulus and } \\
\text { Fracture Thoughness } \\
\text { are useful for other type } \\
\text { of calculations. The } \\
\text { standard femoral head } \\
\text { used diameter is } 28 \mathrm{~mm} \text {. } \\
\text { Cast Co-Cr alloy hardness } \\
\text { varies in literature. There } \\
\text { are a large number of } \\
\text { Titanium alloys available } \\
\text { with closely hardness. }\end{array}$} \\
\hline
\end{tabular}

Table 3: Material parameters and programming numerical settings.

Optimization Algorithms and Clinical Medical Physics parameters

The method is similar to dual and multiobjective optimization for ceramic THA previously published $[1,2,15,16,33]$. The algorithms implemented are based on classical Archard's model $[1,2,15,16,33]$, but with vector-matrix and units modifications [Casesnoves Algorithm , 2020-1]. A variant from this model with evoluted algorithms was developed in previous contributions [Casesnoves, 2018-2020,5]. In the literature, a type of the classical equation for wear optimization of hip implants without hardness reads,

$$
\mathrm{W}=\mathrm{K}_{1} \times\left|\overrightarrow{\mathrm{F}}_{\perp}\right| \times \mathrm{D} ; ;
$$

where $\mathrm{K}_{1}$ is a constant that depends on hardness, $\mathrm{F}$ is load force (vector, and it is taken the normal component), and D is the sliding distance that depends on the velocity. There are several versions for this type of equation published studies $[1,2,18,22$, 24,26,27,28,29,30,31,32,33,34].

However, it is considered the classical formula for this study objectives. The criterion is that hardness must be, for optimization precision, a separated parameter such as,

$$
W=K \frac{L \times X}{H} \text {; }
$$

where $\mathrm{K}$ is wear constant specific for each material, $\mathrm{L}$ biomechanical load ( $\mathrm{N}$, passed here to $\mathrm{kg}$ and $\mathrm{mm}$ ), X sliding distance of the acetabular semi-spehere of the implant (mm), $\mathrm{W}$ is wear $\left(\mathrm{mm}^{3}\right)$, and $\mathrm{H}$ is the hardness of the implant material (MPa, here it is used always $\mathrm{kg}$ and $\mathrm{mm}$ ).

Hence, for Least Squares optimization,

minimize,

$$
\left\|\vec{W}-\vec{K} \frac{\vec{L} \times \vec{X}}{\vec{H}}\right\|_{2}^{2} \cong 0 ;
$$

subject to (generically and with vector-matrix calculus),

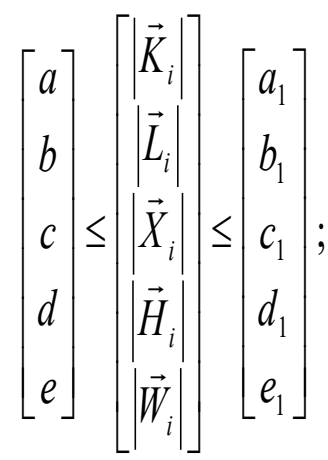

where $\mathrm{K}$ is wear constant specific for each material, $\mathrm{L}$ biomechanical load (vector, $\mathrm{N}$, passed here to $\mathrm{kg}$ and $\mathrm{mm}$ ), $\mathrm{X}$ sliding distance of the acetabular semi-spehere of the implant (vector, $\mathrm{mm}$ ), $\mathrm{W}$ is wear (vector, $\mathrm{mm}^{3}$ ), and $\mathrm{H}$ is the hardness of the implant material (vector, MPa, here it is used always $\mathrm{kg}$ and $\mathrm{mm}$ ). $\mathrm{X}$ is measured as the number of rotations of the implant multiplied by about half distance of its circular-spherical length. However, in this paper is better approximated according to human biomechanics and kinesiology. The average rotation of femur head cannot reach $180^{\circ}$ at any biomechanical movement in common patients. This is valid for flexion, extension, flexion-rotation, extensionrotation, abduction, adduction, external/internal rotation, or combinations of these $[18,19,31]$. For the program settings, one cycle is taken as the length corresponding to the maximum kinesiologic rotation angle. The maximum femur rotation angle value is $145^{\circ}$ in flexion. In the software, this magnitude is implemented. That is, Mc of rotation length is calculated: circumference implant-head radius $\mathrm{R}$ by $\pi$ for a factor of angle of $145^{\circ}$ and by $10^{6}$. Therefore, the erosion in vitro data resulted from this optimization always has to be considered as the maximum angle possible. Number of rotations also depend of the individual patient factors. These could be age, 
daily physical activity, muscular type, race, genetic heritage, associated diseases, country, sport habits, profession, climate, etc.

The load for vector $\mathrm{L}$ was taken as in previous ceramic contribution [1]. Its magnitude to be implemented is rather difficult because usually the load is divided in $\mathrm{X}, \mathrm{Y}, \mathrm{Z}$ components [1]. Average values and/or forces resultant values are taken. For nonlinear optimization, the average values will be implemented in the program [1,26]. In this study, a load of around $200 \%$ of body weight $(200 \% \mathrm{BW})$ is applied for optimization constraints, according to the most usual values of literature $[1,2,3,27,19,20,26]$. Constraints for load are set from a $50 \mathrm{~kg}$ patient till a $80 \mathrm{~kg}$ patient. $50 \mathrm{~kg}$ corresponds, for example, to the body weight of a lightweight patient, or any elderly women who present a high incidence/prevalence of femur head fractures.

The OF with $\mathrm{L}_{2}$ Norm that is used, [Casesnoves Algorithm, 2020-1], without fixed constraints reads,

minimize,

$$
\begin{aligned}
& \|\left. F(\vec{W}, \vec{K}, \vec{H}, \vec{L}, \vec{X})\right|_{2} ^{2} \cong \ldots \\
& . \cong \sum_{i=1}^{i=N} \sum_{j=1}^{j=N} \ldots \\
& \cdot \sum_{k=1}^{k=N}\left(F_{i j k}\left(W_{i j k}, K_{i j k}, H_{i j k}, L_{i j k}, X_{i j k}\right)^{2}+.\right. \\
& \left..+F_{N}\left(W_{N, N, N}, K_{N, N, N}, H_{N, N, N}, L_{N, N, N}, X_{N, N, N}\right)^{2}\right)
\end{aligned}
$$

subject generically to,

$\left[\begin{array}{l}a \\ b \\ c \\ d \\ e\end{array}\right] \leq\left[\begin{array}{l}\left|K_{i}\right| \\ \left|L_{i}\right| \\ \left|X_{i}\right| \\ \left|H_{i}\right| \\ \left|W_{i}\right|\end{array}\right] \leq\left[\begin{array}{l}a_{1} \\ b_{1} \\ c_{1} \\ d_{1} \\ e_{1}\end{array}\right]$

where the constraints values (a-e), will be detailed in (5). $\mathrm{K}$ is wear constant specific for each material, L biomechanical load (vector, $\mathrm{N}$, passed here to $\mathrm{kg}$ and $\mathrm{mm}$ ), $\mathrm{X}$ sliding distance of the acetabular semi-spehere of the implant (vector, $\mathrm{mm}$ ), W is wear (vector, $\mathrm{mm}^{3}$ ), and $\mathrm{H}$ is the hardness of the implant material (vector, $\mathrm{MPa}$, here it is used always $\mathrm{kg}$ and $\mathrm{mm}$ ). The software and mathematical methods of this contribution constitute both an improved evolution and evoluted programs from previous publications in ceramic and metal THA $[1,2,1$ $8,22,24,26,27,28,29,30,31,32,33,34]$ with Matlab. Fortran 90, [24], was used to check/validate the numerical precision of the results. GNU Octave and Freemat [18,22,24,32], was used to verify 3D Interior Optimization Figures 5-9. The variations/ improvements are usage of 2D Graphical Optimization and 3D Interior Optimization methods in Matlab and GNU Octave Systems. In every case, programming involves different structure, subroutines, and patterns. $\mathrm{K}$ is the principal variable for optimization. The reason is that with a multiobjective $\mathrm{K}$ parameter it is possible to carry out in vitro simulations in the materials selection process. The hardness for simulations in vitro, within the optimization hardness interval, could be therefore different than the metal types of Table 3. Therefore, the least-squares OF inverse algorithm [Casesnoves, 2021,1,2,24] implemented constraints are,

min mize $O F$, subject to,

$N=2 \times 10^{6}$,

$W \in \overrightarrow{\mathrm{W}}, H \in \vec{H}, L \in \vec{L}, X \in \vec{X}$,

$0.001 \leq|W| \leq 2.000 \mathrm{~mm}^{3}$,

$1,863 \times 10^{6} \leq|H| \leq 35303940[\mathrm{~kg}, \mathrm{~mm}]$;

$7.5 \times 10^{4} \times 9.8066 \leq|L| \leq 2.0 \times 10^{5} \times 9.8066(200 \% B W)$;

$\|\overrightarrow{\mathrm{x}}\|=\pi \times 28 \times\left(145 \times 10^{6}\right) / 180(1$ million cycles $) ;$

Provided this OF and constraints, running program time resulted be between 2-8 minutes-with a standard current microprocessor and pc memory. 3D Interior Optimization Matlab plots take longer time because there are $3 \mathrm{D}$ volume matrices, a number of nested arrays and patters compared to 2D Graphical Optimization. Scale factors are essential in both types of imaging suroutines and codes for sharp visualization $[1,2,5,24]$. Image processing and computer vision programsentences and commands are essential to obtain good graphics. 3D Interior Optimization GNU Octave plots take longer time than Matlab and provide with good computer vision imaging. GNU Octave Image Processing programs are set with different subroutines compared to Matlab but similar software, arrays, nested loops and patterns than Matlab [27,28,38,40].

\section{Results}

The results are presented both numerically and in graphics with Matlab. Numerical results are detailed in Table 4. Graphics software was designed to show local minimum in function of several parameters. In Table 4, the multiobjective nonlinear optimization for all metals of the selected group. Figs 2-4 show the model 2D Graphical Optimization. The curves and areas correspond to model objective function (Y axis) related to parameter values (X axis). Nonlinear multibjective 2D optimization matrix was set with $2 \times 10^{6}$ functions. Running time was about 2-8 minutes to obtain local minima and graphics. The 2D coloured-surfaces obtained are filled with all the OF values for those 2 million functions. As it occurred for THA ceramic modelling optimization, [2], it is demonstrated the exclusive existence of local minima. Residual-norms are low considering the 2 million OFs of the optimization matrix. 3D Matlab Interior Optimization graphs are shown in Figures $5,6,7$. These prove the consistency of 2D Graphical and Numerical Optimization. Freemat [18,22,24,32], was used to verify 3D graphics and Fortran [24], for all numerical results. 3D GNU Octave Interior Optimization graphs are shown in Figures 8,9. These programs are different and provide with good images. GNU Octave Image Processing tools show be efficacious although slower than Matlab.

\section{Numerical Optimization Results}

Table 4 shows summary of mutiobjective optimization numerical results. The optimal $\mathrm{K}$ for a suitable local minimum of the model is $56.323551 \times 10^{-9}$. The model optimization has not a global minimum, [1,2], and after several tentatives 
with different initial guess vectors the lowest residual-norm found corresponds to this figure of $\mathrm{K}$. Optimal hardness is approximately $2.900 \times 10^{7}$ [all in $\mathrm{Kg}, \mathrm{mm}$ ]. Residual-norm value is low, given the number of functions of the OF. With 2D Graphical optimization and 3D Interior Optimization search, a series of optimal intervals were found in graphs with cursor. These 3D results confirm/validate the 2D Graphical Optimization numbers.

\begin{tabular}{|c|c|c|}
\hline Material & $\begin{array}{l}\text { Optimal K } \\
\text { adimensional }\end{array}$ & $\begin{array}{l}\mathrm{O} \text { p t i m a } 1 \\
\text { hardness } \\
(\mathrm{kg}, \mathrm{mm})\end{array}$ \\
\hline Stainless Steel & \multirow{3}{*}{$\begin{array}{l}56.3236 \times 10^{-9} \\
{[\text { truncated] }}\end{array}$} & \multirow{3}{*}{$\begin{array}{l}2.900 \times 10^{7} \\
\text { [truncated] }\end{array}$} \\
\hline $\begin{array}{l}\text { Co-Cr-Mo } \\
\text { (Ni, Fe, } \\
\text { Co-based-alloys) }\end{array}$ & & \\
\hline Titanium alloys & & \\
\hline $\begin{array}{l}\text { RES IDUAL-NORM } \\
\text { FOR OPTIMAL K }\end{array}$ & \multicolumn{2}{|c|}{$1.311 \times 10^{3} \quad$ [truncated $]$} \\
\hline $\begin{array}{l}\text { OPTIMAL } \\
\text { DIFFERENCE } \\
\text { [EXPERIMENTAL - } \\
\text { MODEL] }\end{array}$ & \multicolumn{2}{|c|}{0.005 [truncated] } \\
\hline \multicolumn{3}{|c|}{$\begin{array}{l}\text { 3D GRAPHICAL-INTERIOR OPTIMIZATION } \\
\text { RESULTS }\end{array}$} \\
\hline $\begin{array}{l}\text { 3D MATRIX } \\
\text { PROGRAM }\end{array}$ & \multicolumn{2}{|c|}{$\begin{array}{l}\text { Validation } \\
\text { of K optimal parameter. } \\
\text { In chart. Validation of erosion } \\
\text { rises when Hardness decreases }\end{array}$} \\
\hline $\begin{array}{l}\text { OPTIMAL K } \\
\text { INTERVAL }\end{array}$ & \multicolumn{2}{|c|}{ 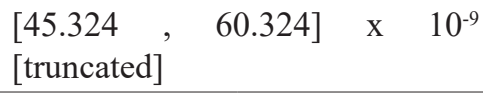 } \\
\hline $\begin{array}{l}\text { OPTIMALHARDNESS } \\
\text { INTERVAL }\end{array}$ & \multicolumn{2}{|c|}{$\begin{array}{l}{[1.811,2.932] \times 10^{7}} \\
{[\text { truncated }]}\end{array}$} \\
\hline $\begin{array}{l}\text { O P T I M A L } \\
\text { DIFFERENCE } \\
\text { [EXPERIMENTAL - } \\
\text { MODEL] } \\
\text { INTERVAL }\end{array}$ & \multicolumn{2}{|l|}{$\begin{array}{l}{[0.005,0.083]} \\
{[\text { truncated }]}\end{array}$} \\
\hline
\end{tabular}

Table 4: Multifunctional numerical results for 2D Graphical Optimization and 3D Interior Optimization

\section{D Graphical Optimization Results}

First optimization program has two parts. The first one is related to numerical results for $\mathrm{K}$ and optimal hardness. The second is the plotting of 2D Graphical Optimization. Table 4 details numerical results. Figures 2, 3 show the 2D Graphical optimization results for about $2 \times 10^{6}$ functions. Figure 2 demonstrates the optimization region and the decrease of erosion when hardness increases and the difference between experimental values and model figures. Figure 3 shows the optimal hardness obtained verification with 2D Graphical Optimization. The optimal K value got was 56.3236 x $10^{-9}$. The optimal hardness obtained is $2.900 \times 10^{7}$ approximately . All numerical values are expressed in $\mathrm{mm}, \mathrm{mm}^{3}$, and $\mathrm{kg}$. The K-metal magnitude results be higher than K-ceramic standard parameter for ceramic THA optimization [1,2].

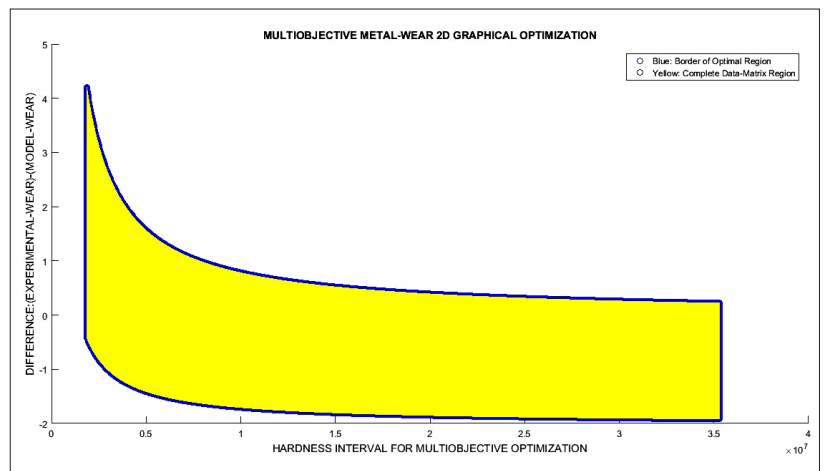

Figure 2: Optimization region and the decrease of erosion when hardness increases and the difference between experimental values and model figures. There is a peak at low hardness that overlaps the experimental interval. This is comfirmed also in 3D Interior Optimization graphs. However, in general all the harness interval is within the experimental numerical interval region.

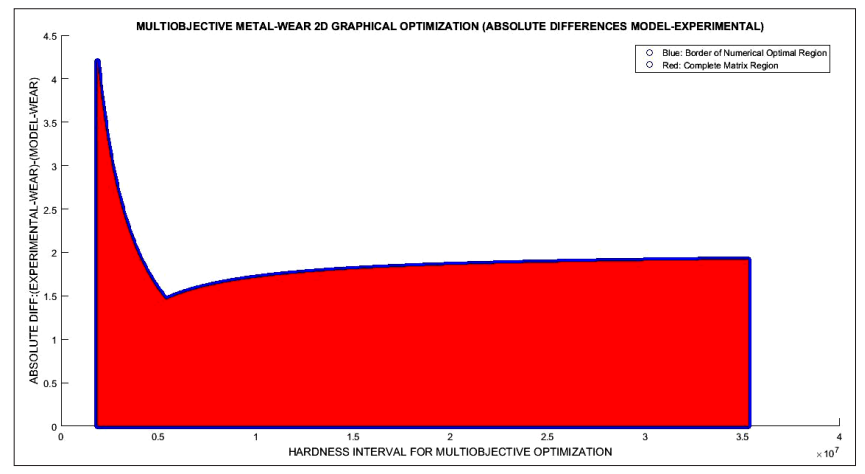

Figure 3: Optimal hardness obtained verification with 2D Graphical Optimization. Numerical values can be obtained both with software and graphics. The minimum-peak at [1.5, $\left.0.5 \times 10^{7}\right]$ in this case has no significance for optimization. The optimal hardness corresponds to the average value for almost all region located at $2 \times 10^{7}$.

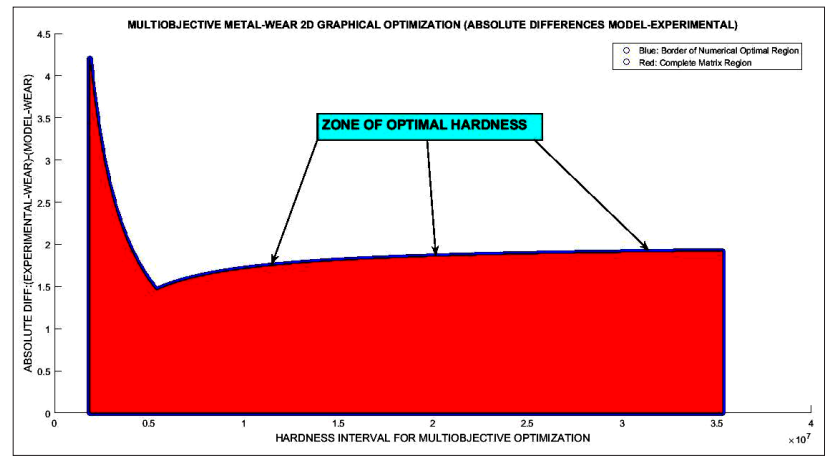

Figure 4: Optimal hardness obtained verification with 2D Graphical Optimization. Numerical value can be obtained both with software and graphics. That value is approximately at the same numerical distance from the higest region values and the lowest region figures. The peak at very low hardness is not taken into account, that surpasses the optimization experimental interval. 
3D Interior Optimization Results

Second optimization program(s) are based on nested arrays and a 3D volume-matrix with 106 elements (Figures 5,6,7 second program) implemented in different program structures for Matlab and GNU Octave. $\mathrm{X}$ axis shows $\mathrm{K}$ interval around optimal value obtained with optimization program. $\mathrm{Y}$ axis shows the hardness interval. All numerical values are expressed in $\mathrm{mm}, \mathrm{mm}^{3}$, and $\mathrm{kg}$. The software design was rather complicated $[1,2,24]$. Matlab programs have differents subroutines, arrays, and patterns compared to GNU octave. Running time in GNU Octave is longer than Matlab but image quality is almost equal.

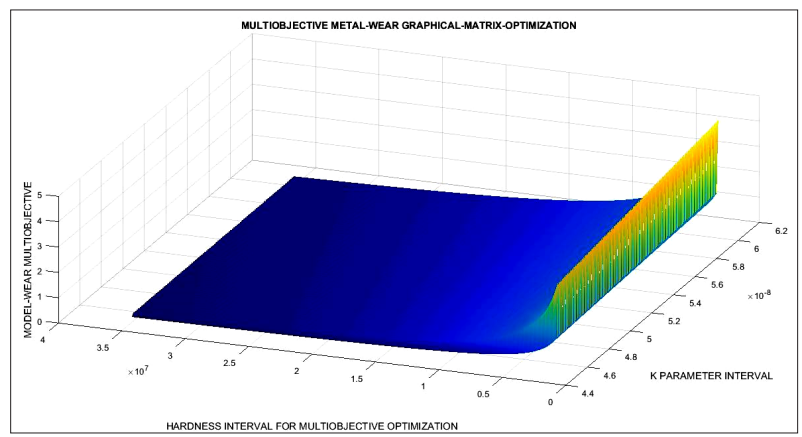

Figure 5: The 3D Interior Optimization matrix image with $10^{6}$ elements. At $\mathrm{Z}$ axis the wear model in absolute value. It proves that erosion is higher when hardness is lower and load is higher. Matrix has $10^{6}$ elements and was set with $\mathrm{K}$ optimal interval that was obtained with $2 \mathrm{D}$ optimization algorithm. The program was rather difficult with several long nested patterns. Note that almost all the surface falls within experimental interval, matching model-experimental consistency. The 3D peak corresponds to the 2D peaks of Figures 2-4.

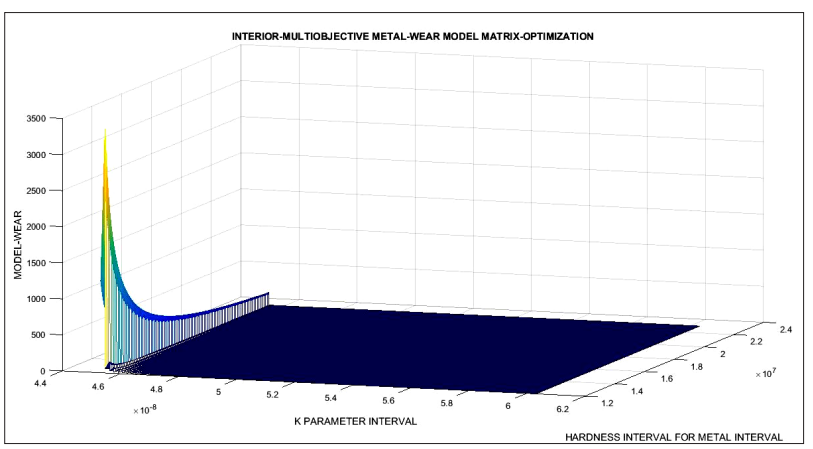

Figure 6: The 3D Interior Optimization matrix image with $10^{6}$ elements, but setting at $\mathrm{Z}$ axis the Objective Function. $\mathrm{OF}$ is almost null for most of surface. It also proves that erosion is higher when hardness is lower and load is higher. Matrix has $10^{6}$ elements and was set with $\mathrm{K}$ optimal interval that was obtained with 2D optimization algorithm. The program was rather difficult than previous image with several long nested patterns. Note that almost all the surface falls within experimental interval, matching model-experimental consistency. The 3D peak corresponds to the 2D peaks of Figures 2-4.

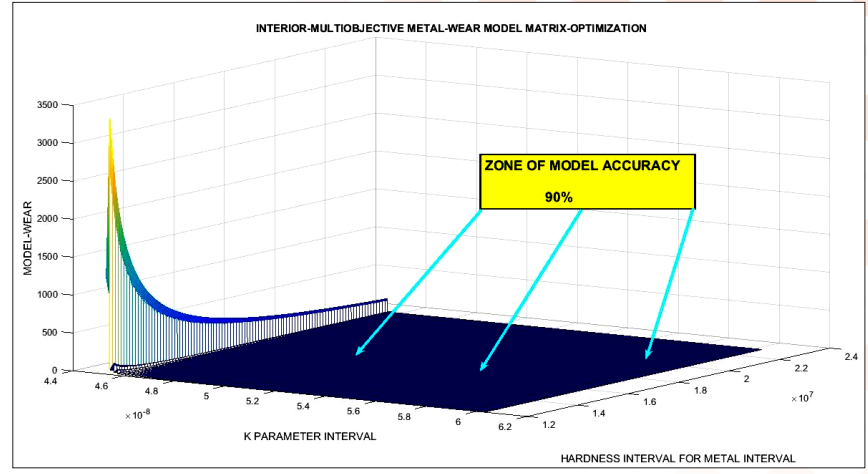

Figure 7: Demonstration of $90 \%$ accuracy zone for the model. The 3D Interior Optimization matrix image with $10^{6}$ elements, but setting at $\mathrm{Z}$ axis the Objective Function. OF is almost null for most of surface. It also proves that erosion is higher when hardness is lower and load is higher. Matrix has $10^{6}$ elements and was set with $\mathrm{K}$ optimal interval that was obtained with $2 \mathrm{D}$ optimization algorithm. Imaging processing commands were used to obtain this picture. The reason for the big magnitude of the peak at lower hardness is that in the program was implemented a variant of the model formula. In this algebraicvariant the experimental wear is set at denominator, and when it approaches to zero, the absolute difference of the model with the experimental tends to very high values. However, this algebraic-variant of the model with the optimal adimensional $\mathrm{K}$ is accurate at $90 \%$.

\section{GNU Octave software comparative optimization}

Recently, GNU Octave software shows a number of new imaging processing tools. These computer vision programming tools give a good quality images/graphs. Figures 8 and 9 show how the Matlab graphs from Figures 5-7 can be performed with similar software in GNU Octave. The results are fine with sharp images. Time for getting an image is about 30 seconds longer than Matlab. GNU Octave Imaging tools are more simple than Matlab, but work correctly and fast.

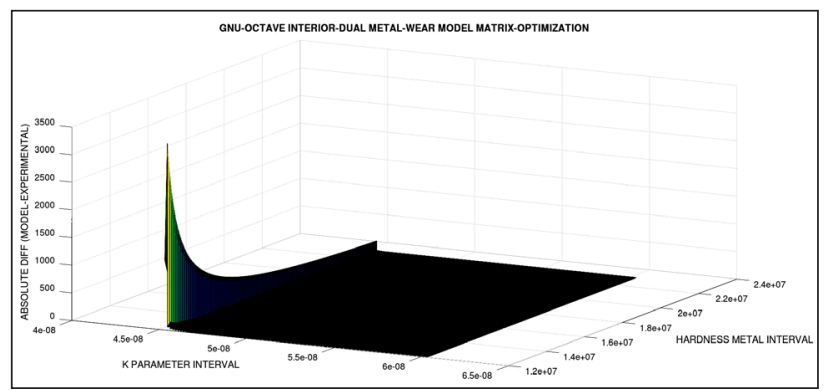

Figure 8: GNU Octave 3D Interior Optimization matrix image with $10^{6}$ elements, but setting at $\mathrm{Z}$ axis the Objective Function. $\mathrm{OF}$ is almost null for most of surface. It also proves that erosion is higher when hardness is lower and load is higher. Matrix has $10^{6}$ elements and was set with $\mathrm{K}$ optimal interval that was obtained with 2D optimization algorithm. The program running time is longer compared to Matlab. Note that almost all the surface falls within experimental interval, matching model-experimental consistency. The 3D peak corresponds to the 2D peaks of Figures 2-4. The reason for the big magnitude of the peak at lower hardness is that in the program was 
implemented a variant of the model formula. In this algebraicvariant the experimental wear is set at denominator, and when it approaches to zero, the absolute difference of the model with the experimental tends to very high values. However, this algebraic-variant of the model with the optimal adimensional $\mathrm{K}$ is accurate at $90 \%$.

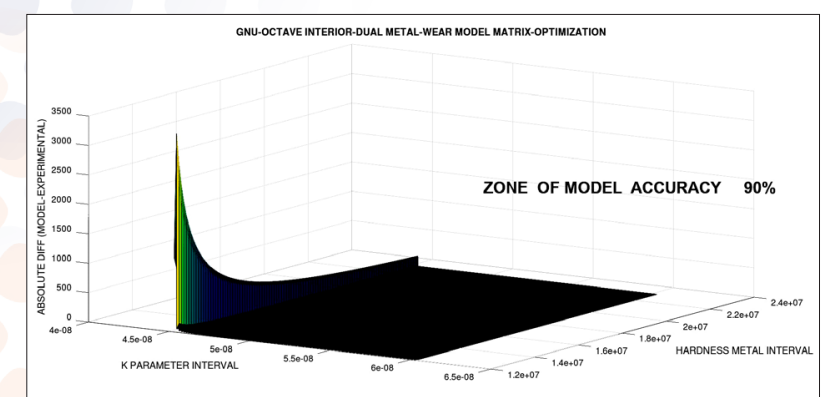

Figure 9: GNU Octave demonstration of 90\% accuracy zone for the model. The 3D Interior Optimization matrix image with $10^{6}$ elements, but setting at $\mathrm{Z}$ axis the Objective Function. OF is almost null for most of surface - both in Matlab and GNU Octave. It also proves that erosion is higher when hardness is lower and load is higher. Matrix has $10^{6}$ elements and was set with $\mathrm{K}$ optimal interval that was obtained with $2 \mathrm{D}$ optimization algorithm. Octave Imaging Processing commands, simpler than Matlab, were used to obtain this picture.

\section{Validation of Numerical Results}

To verify the numerical results the optimal values are implemented in the model as follows,

$$
\begin{aligned}
& \mid K(\text { optimal }) \times \frac{\text { Load }(\text { average }) \times M c}{\text { Hardness }(\text { optimal })} \mid= \\
& =56.3236 \times 10^{-9} \times \frac{1.3484 \times 10^{6} \times M c}{2.9000 \times 10^{7}}= \\
& =0.1486 \mathrm{~mm}^{3} \in[0.001,2.000] ;
\end{aligned}
$$

As it was wanted to prove. The value 0.1486 is within the experimental interval $[0.001,2.000]$. When implementing hardness magnitudes around $2.5 \times 10^{7}$, the erosion prediction comes near to the experimental erosion interval upper bound

Medical Physics and Biomedical Engineering applications There is a large number/varieties of applications for the results of the study. Table 5 shows four branchs in this line. Namely, theoretical-mathematical, experimental, clinical and extrapolated applications. Once a model has been verified/

\begin{tabular}{|c|c|}
\hline \multicolumn{2}{|c|}{$\begin{array}{l}\text { COMPUTATIONAL MEDICAL PHYSICS } \\
\text { BIOENGINEERING APPLICATIONS }\end{array}$} \\
\hline \multicolumn{2}{|c|}{ THEORETICAL-MATHEMATICAL } \\
\hline MODELLING (1) & $\begin{array}{l}\text { CT Scans data to measure } \\
\text { with FE wear in post- } \\
\text { operative, } \\
\text { Analytical models can be } \\
\text { set in FE modelling within } \\
\text { elements }\end{array}$ \\
\hline MODELLING (2) & $\begin{array}{l}\text { Prediction of wear after THA } \\
\text { implant is set, short-term and } \\
\text { long-term }\end{array}$ \\
\hline \multicolumn{2}{|l|}{ EXPERIMENTAL } \\
\hline $\begin{array}{l}\text { LABORATORY } \\
\text { METHODS AND } \\
\text { SIMULATIONS }\end{array}$ & $\begin{array}{l}\text { Improvements in simulation } \\
\text { lab tasks getting more } \\
\text { accuracy in modelling } \\
\text { Design of new models } \\
\text { Finite Elements method } \\
\text { applications }\end{array}$ \\
\hline \multicolumn{2}{|l|}{ CLINICAL } \\
\hline HIP PROSTHESES & \begin{tabular}{|l} 
Decrease of \\
$\begin{array}{l}\text { complications for } \\
\text { increase }\end{array}$
\end{tabular} \\
\hline $\begin{array}{l}\text { THA } \\
\text { ORTHOPEDICS }\end{array}$ & \begin{tabular}{|lr} 
Prevent & dislocation \\
metallosis and soft-tissue \\
damage
\end{tabular} \\
\hline PRE-OPERATION & $\begin{array}{l}\text { Pre-operative simulations for } \\
\text { operation improvements at } \\
\text { theatre }\end{array}$ \\
\hline POST-OPERATION & $\begin{array}{l}\text { Prevent dislocation,pain, } \\
\text { referred radicular pain, } \\
\text { throchanteric bursitis, and } \\
\text { ALTR (adverse local tissue } \\
\text { reactions) }\end{array}$ \\
\hline REHABILITATION & $\begin{array}{ll}\text { Getting } & \text { faster/better } \\
\text { rehabilitation }\end{array}$ \\
\hline DEFORMATIONS & $\begin{array}{l}\text { Improve of THA for severe } \\
\text { hip deformity }\end{array}$ \\
\hline PREVENTIVE MEDICINE & $\begin{array}{l}\text { Statistics for prevention } \\
\text { of incidence/prevalence of } \\
\text { hip joint diseases, statistic } \\
\text { models for disease evolution }\end{array}$ \\
\hline \multicolumn{2}{|c|}{ EXTRAPOLATED APPLICATIONS } \\
\hline $\begin{array}{l}\text { KNEE ARTHROPLASTY } \\
\text { MODELS }\end{array}$ & $\begin{array}{l}\text { Erosion/wear modelling in } \\
\text { knee arthroplasty similarity } \\
\text { improvements }\end{array}$ \\
\hline $\begin{array}{l}\text { OTHER ARTICULATIONS } \\
\text { MODELING }\end{array}$ & $\begin{array}{l}\text { Extrapolable methods for } \\
\text { other articulation wear } \\
\text { modelling }\end{array}$ \\
\hline SPORT MEDICINE & $\begin{array}{l}\text { Modelling for high- } \\
\text { performance } \\
\text { prostheses }\end{array}$ \\
\hline
\end{tabular}
fitted with experimental and clinical data, the other aplications emerge easygoing.
Table 5: Applications of the study in several theoretical and practical areas. 


\section{Discussion and Conclusions}

The result of this further research, [1,2], in THA modelling are numerical, graphical, and software-computational. The optimal numerical achievement is a $\mathrm{K}$-adimensional constant for the model. The graphical-imaging results are 2D Graphical Optimization and 3D Interior Optimization useful charts. Sofware design-calculations constitute a series of programs with accurate results - they have been proven along a series of studies [1,2] for this model, and show the exclusive existence of local minima for this model. Another result in 2D Graphical Optimization and 3D Interior Optimization is the demonstration of the Image Processing and Computational Vision Toolboxes practical functionality in nonlinear optimization. Following further software development than previous contributions, two Programming Systems are used/compared. Namely, Matlab and GNU Octave ones. Both Systems show/validate the objective function magnitude minima for the model.

Then, an inverse multifunctional optimization study was presented with a classical wear model improved and an original programming algorithm. The model was applied on material wear for 3 groups of metal THA. The selected materials were Stainless Steel, Co-Cr-Mo (Ni, Fe, Co-based-alloys) and Titanium alloys.

The software implemented for the algorithm [Casesnoves, 2021], provided a series of OF local minima for optimal K. The best selection among these resulted in an acceptable standard $\mathrm{K}$ parameter and optimal model hardness. The magnitude order of this $\mathrm{K}$ is highen than tan ceramic THA one obtained in previous investigations [1,2]. The graphs show a peak of magnitude difference at very low values of hardness. This is caused by the large multiobjective optimization interval. It is also due in 3D Interior Optimization graphics to the algebraic-variant model formula that was implemented in the 3D array program. Accuracy of model shows be around higher than $90 \%$. Efficacious usage of the study are theoretical and experimental—which are syneric and complementary. Namely, theoretical improvements for the model and its advanced theoretical/experimental fitness. Experimental applications comprise the utility of the $\mathrm{K}$ parameter and optimal hardness any metal-material wear prediction within the interval model whose parameters were computationally chosen. Residualsnorms in this optimization performance are acceptable of $10^{3}$ magnitude order. Graphs presented resulted clear/sharp with acceptable visualization. Running time for programs is from 2 to 7 minutes. If matrix is higher than $10^{6}$ elements in 3D Interior Optimization, the images late about 10-20 minutes. GNU Octave image processing takes longer than Matlab but provides with good imaging quality. Its software was implemented with different subroutines and options, but similar arrays, patterns and nested loops.

The objective of the study can be extrapolated for other in vitro THA metal experimental. Provided the hardness magnitude is within the optimization interval and the chemical composition is not excessively different, simulations are feasible. Improvements in algorithms, software, imaging processing, and model design emerge from these findings. Mathematical modelling optimization method(s) are also extrapolable to other similar biomechanical-orthopaedic wear models. In brief, an accurate and efficient multiobjective optimization to obtain functional modelling parameters in metal THA erosion was presented. Applications in Medical Physics come from all this biotribological modelling improvements $[43,44]$.

\section{Scientific Ethics Standards}

2D/3D Graphical-Optimization Methods were created by Dr Francisco Casesnoves on December 2016, and Interior Optimization Methods in 2019. This software was originally developed by author. This article has a few previous paper information, whose inclusion is essential to make the contribution understandable. The nonlinear optimization software was improved from previous contributions in subroutines modifications, patters, loops, graphics and optimal visualization with GNU Octave new software. This study was carried out, and their contents are done according to the European Union Technology and Science Ethics. Reference, 'European Textbook on Ethics in Research'. European Commission, Directorate-General for Research. Unit L3. Governance and Ethics. European Research Area. Science and Society. EUR 24452 EN [43,44]. And based on 'The European Code of Conduct for Research Integrity'. Revised Edition. ALLEA. 2017.year. This research was completely done by the author, the computational-software, calculations, images, mathematical propositions and statements, reference citations, and text is original for the author. When a mathematical statement, proposition or theorem is presented, demonstration is always included. When anything is taken from a source, it is adequately recognized. Ideas from previous publications were emphasized due to a clarification aim $[43,44]$.

\section{References}

1. Casesnoves, F (2021) Multiobjective Optimization for Ceramic Hip Arthroplasty with Medical Physics Applications. Int. J. Sci. Res. Comput. Sci. Eng. Inf. Technol. 2021, 7, 582-598, ISSN: 2456-3307, https://doi. org/10.32628/CSEIT21738.

2. Casesnoves, F (2018) Nonlinear comparative optimization for biomaterials wear in artificial implants technology. In Proceedings of the Applied Chemistry and Materials Science RTU2018 Conference Proceedings. Latvia. October 2018.

3. Merola, M.;Affatato, S (2019) Materials for Hip Prostheses: A Review of Wear and Loading Considerations. Materials 2019, 12, 495, doi:10.3390/ma12030495.

4. Navarro, N (2008) Biomaterials in orthopaedics. $J$. R. Soc. Interface 2008, 5, 1137-1158, DOI:10.1098/ rsif.2008.0151.2008.

5. Kurtz, S (2014) Advances in Zirconia Toughened Alumina Biomaterials for Total Joint Replacement. J. Mech. Behav. Biomed. Mater. 2014, 31, 107-116, doi:10.1016/j.jmbbm. 2013.03.022. 2014.

6. Sachin, G.; Mankar, A (2016) Biomaterials in Hip Joint Replacement. Int. J. Mater. Sci. Eng. 2016, 4, pp. 113125, doi:10.17706/ijmse.2016.4.2.113-125. 
7. Li, Y.; Yang, C.; Zhao, H.; Qu, S.; Li, X.; Li, Y (2014) New Developments of Ti-Based Alloys for Biomedical Applications. Materials 2014, 7, 1709-1800, doi:10.3390/ ma7031709.

8. Kolli, R.; Devaraj, A (2018) A Review of Metastable Beta Titanium Alloys. Metals 2018, 8, 506, DOI:10.3390/ met8070506.

9. Holzwarth, U.; Cotogno, G (2012) Total Hip Arthroplasty. JRC Scientific and Policy Reports; European Commission: Brussels, Belgium, 2012.

10. Delimar, D (2018) Femoral head wear and metallosis caused by damaged titanium porous coating after primary metal-on-polyethylene total hip arthroplasty: A case report. Croat. Med. J. 2018, 59, 253-257, DOI:10.3325/ cmj.2018.59.253.

11. Zhang, M.; Fan, Y (2015) Computational Biomechanics of the Musculoskeletal System; CRC Press: Boca Raton, FL, USA, 2015.

12. Dreinhöfer, K.; Dieppe, P.; Günther, K.; Puhl, W (2009) Eurohip. Health Technology Assessment of Hip Arthroplasty in Europe; Springer: Berlin/Heidelberg, Germany, 2009.

13. Casesnoves, F (2018) 2D computational-numerical hardness comparison between Fe-based hardfaces with WC-Co reinforcements for Integral-Differential modelling. Trans. Tech. 2018, 762, 330-338, DOI:10.4028/www. scientific.net/KEM.762.330. ISSN: 1662-9795.

14. Hutchings, I.; Shipway, P (2017) Tribology Friction and Wear of Engineering Materials, 2nd ed.; Elsevier: Amsterdam, The Netherlands, 2017.

15. Shen, X.; Lei, C.; Li, R (2010) Numerical Simulation of Sliding Wear Based on Archard Model. In Proceedings of the 2010 International Conference on Mechanic Automation and Control Engineering, Wuhan, China, 2628 June 2010. DOI:10.1109/MACE.2010.5535855.

16. Affatato, S.; Brando, D (2012) Introduction to Wear Phenomena of Orthopaedic Implants; Woodhead Publishing: Sawston, UK, 2012.

17. Matsoukas, G.; Kim, Y (2009) Design Optimization of a Total Hip Prosthesis for Wear Reduction. J. Biomech. Eng. 2009, 131, 051003.

18. Casesnoves, F.; Antonov, M.; Kulu, P (2016) Mathematical models for erosion and corrosion in power plants. A review of applicable modelling optimization techniques. In Proceedings of RUTCON2016 Power Engineering Conference, Riga, Latvia, $13^{\text {th }}$ October. 2016.

19. Galante, J.; Rostoker, W (2014) Wear in Total Hip Prostheses. Acta Orthop. Scand. 2014, 43, 1-46, DOI:10.3109/ort.1972.43.suppl-145.01.

20. Mattei, L.; DiPuccio, F.; Piccigallo, B.; Ciulli, E (2011) Lubrication and wear modelling of artificial hip joints: A review. Tribol. Int. 2011, 44: 532-549.

21. Jennings, L (2012) Enhancing the safety and reliability of joint replacement implants. Orthop. Trauma 2012, 26: 246-252.

22. Casesnoves, F (2019) Die Numerische ReuleauxMethode Rechnerische und Dynamische Grundlagen mit Anwendungen (Erster Teil); Sciencia Scripts: 2019; ISBN-13: 978-620-0-89560-8, ISBN-10: 6200895600.
23. Kulu, P.; Casesnoves, F.; Simson, T.; Tarbe, R (2017) Prediction of abrasive impact wear of composite hardfacings. Solid State Phenomena. In Proceedings of the $26^{\text {th }}$ International Baltic Conference on Materials Engineering, 2017; Lithuania. October 2017. Trans Tech Publications: Bäch, Switzerland, 2017; Volume 267, pp. 201-206; ISSN: 1662-9779, doi:10.4028/www.scientific. net/SSP.267.201.

24. Casesnoves, F (2018) Mathematical Models and Optimization of Erosion and Corrosion. Ph.D. Thesis, Taltech University, Tallinn, Estonia. 14 December. 2018. ISSN 25856898.

25. Saifuddin, A.; Blease, S.; Macsweeney, E (2003) Axial loaded MRI of the lumbar spine. Clin. Radiol. 2003, 58: 661-671.

26. Damm, P (2014) Loading of Total Hip Joint Replacements. Ph.D. Thesis, Technischen Universität, Berlin, Germany, 2014.

27. Casesnoves, F (2019) The Numerical Reuleaux Method, a Computational and Dynamical Base with Applications. First Part; Lambert Academic Publishing: 2019; Republic of Moldava. ISBN-10 3659917478.

28. Casesnoves, F (2007) Large-Scale Matlab Optimization Toolbox (MOT) Computing Methods in Radiotherapy Inverse Treatment Planning. High Performance Computing Meeting; Nottingham University: Nottingham, UK, 2007.

29. Casesnoves, F (2007) A Monte-Carlo Optimization method for the movement analysis of pseudo-rigid bodies. In Proceedings of the 10th SIAM Conference in Geometric Design and Computing, San Antonio, TX, USA, 4-8 November 2007; Contributed Talk.

30. Casesnoves, F. (2011) Theory and Primary Computational Simulations of the Numerical Reuleaux Method (NRM)', Casesnoves, Francisco. Int. J. Math. Computation. 2011, 13, pp. 89-111. Available online: http://www.ceser.in/ ceserp/index.php/ijmc/issue/view/119 (accessed on 28 June 2021).

31. Casesnoves, F (2015) Applied Inverse Methods for Optimal Geometrical-Mechanical Deformation of Lumbar artificial Disks/Implants with Numerical Reuleaux Method. 2D Comparative Simulations and Formulation. Comput. Sci. Appl. 2015, 2, 1-10. Available online: www. ethanpublishing.com (accessed on 28 June 2021).

32. Casesnoves, F (2018) Inverse methods and IntegralDifferential model demonstration for optimal mechanical operation of power plants-numerical graphical optimization for second generation of tribology models. Electr. Control Commun. Eng. 2018, 14: 39-50, DOI:10.2478/ecce-2018-0005.

33. Casesnoves, F.; Surzhenkov, A (2017) Inverse methods for computational simulations and optimization of erosion models in power plants. In Proceedings of the IEEE Proceedings of RUTCON2017 Power Engineering Conference, Riga, Latvia, 5 December 2017. doi:10.1109/ RTUCON.2017.8125630. Electronic ISBN:978-1-53863846-0. USB ISBN: 978-1-5386-3844-6. ISBN: 978-15386-3847-7.

34. Abramobitz, S (1972) Handbook of Mathematical Functions. Appl. Math. Ser. 55. 1972. 
35. Luenberger, G.D (2008) Linear and Nonlinear Programming, $4^{\text {th }}$ ed.; Springer: Berlin/Heidelberg, Germany, 2008.

36. Casesnoves, F (2016) Exact Integral Equation Determination with 3D Wedge Filter Convolution Factor Solution in Radiotherapy. Series of ComputationalProgramming 2D-3D Dosimetry Simulations. Int. J. Sci. Res. Sci. Eng. Technol, pp. 699-715. 2016, 2.

37. Panjabi, M.; White, A (1980) Clinical Biomechanics of the Spine. Lippincott 1980, 42, S3.

38. Casesnoves, F (2021) Software Programming with Lumbar Spine Cadaveric Specimens for Computational Biomedical Applications. Int. J. Sci. Res. Comput. Sci. Eng. Inf. Technol. 2021, 7, 7-13, ISSN: 2456-3307.

39. Surzhenkov, A.; Viljus, M.; Simson, T.; Tarbe, R.; Saarna, M.; Casesnoves, F (2017) Wear resistance and mechanisms of composite hardfacings atabrasive impact erosion wear. J. Phys. 2017, 843, 012060, doi:10.1088/17426596/843/1/012060.

40. Casesnoves, F (2012) Computational Simulations of Vertebral Body for Optimal Instrumentation Design. ASME J. Med. Devices 2012, 6, 021014, http://dx.doi. org/10.1115/1.4006670.

41. Barker, P (2014) The effect of applying tension to the lumbar fasciae on segmental flexion and extension. In Proceedings of $5^{\text {th }}$ International Congress of Low Back and Pelvic Pain, Melbourne, Australia, 10-13 November 2014; pp. 50-52.

42. Galme, S.; Barker, P.; Bhalerao, Y (2016) Biomaterials in Hip Joint Replacement. Int. J. Mater. Sci. Eng. 2016, 4, 113-125.

43. European Textbook on Ethics in Research. European Commission, Directorate-General for Research. Unit L3. Governance and Ethics. European Research Area. Science and Society. EUR 24452 EN. Available online: https://op.europa.eu/en/publication-detail/-/ publication/12567a07-6beb-4998-95cd-8bca103fcf43. (accessed on 28 June 2021).

44. ALLEA (2017) The European Code of Conduct for Research Integrity, Revised ed.; ALLEA: Berlin Barndenburg Academy of Sciences. 2017.

Copyright: (C2021 Francisco Casesnoves. This is an open-access article distributed under the terms of the Creative Commons Attribution License, which permits unrestricted use, distribution, and reproduction in anymedium, provided the original author and source are credited. 